\title{
Renal Hydatid Cyst
}

Ganime ÇOBAN ${ }^{1}$, Zeynalabidin ORHAN² , Senad KALKAN ${ }^{3}$, Ümit TÜZÜN ${ }^{4}$ Nurcan ÜNVER ${ }^{1}$

'Department of Pathology, Bezmialem Vakif University School of Medicine, İstanbul, Turkey

${ }^{2}$ Department of Forensic Medicine, Bezmialem Vakif University School of Medicine, İstanbul, Turkey

${ }^{3}$ Department of Urology, Bezmialem Vakif University School of Medicine, İstanbul, Turkey

${ }^{4}$ Department of Radiology, Bezmialem Vakif University School of Medicine, İstanbul, Turkey

\section{ABSTRACT}

The larval form of Echinococcus granulosus (tapeworm), which causes hydatid cysts, penetrates the intestinal mucosa and settles in tissues and is contracted through animal contact or other ways. The most common location is liver, and renal involvement is very rare. It is usually diagnosed with nonspecific symptoms or incidentally. A kidney lesion was incidentally detected in a 55-year-old female patient who was suffering from chronic diseases and underwent partially nephrectomy. We aim to present this case in which renal hydatid cyst was diagnosed with the help of literature because of its rarity.

Keywords: Kidney, cyst, nephrectomy

\section{Introduction}

Hydatid cyst is a common parasitic disease caused by the settlement of Echinococcus granulosus larvae in the tissues. It is often observed in India, Africa, South America, the central European countries, and Turkey. The most affected organ is the liver $(77 \%-54 \%)$, followed by the lungs $(9 \%-30 \%)$, spleen $(0.9 \%-8 \%)$, kidney $(2 \%-3 \%)$, brain $(1 \%)$, and other organs (1-3).

\section{Case Report}

A 55-year-old female patient who was under follow-up due to rheumatoid arthritis and hypertension visited another hospital owing to dyspnea and fatigue. Thorax computed tomography (CT) of the patient, who had no findings in the examination, was performed to detect lung and pleural involvement owing to rheumatoid arthritis findings. No features were observed in other system examinations. Complete blood count and biochemical values were found within normal limits in the tests performed. In the total urine test, a trace amount of leukocytes and $1(+)$ glucose were found. Rare leukocytes were observed in microscopic observation of the urine sample. The patient visited the urology clinic of our hospital for further evaluation and treatment because a lesion was detected in the upper pole of the right kidney that was in the scope of vision, although no features were observed in the lung and pleura in thorax CT. The liver size had increased minimally in abdominal CT, and cystic or solid lesions were not detected. The spleen was normal. In both kidneys, there were simple cysts, the largest of which was $1 \mathrm{~cm}$ in diameter in the lower pole of the left kidney. A $35 \times 28 \mathrm{~mm}$ lesion that had dense content and contained calcifications in the periphery was observed in the upper pole of the right kidney. Precontrast density was $25-30 \mathrm{HU}$ on average, and an average contrast of 10-15 HU was observed in the postcontrast lateral component. There was ongoing contrast enhancement in the late phase as well (Figure 1). Papillary renal cell carcinoma or degenerative cyst was included in the differential diagnosis of hydatid in the patient in whom clear characterization was not possible on the basis of the imaging features. The patient was investigated in terms of hydatid cyst and did not have a history of contact with animals such as sheep, goats, and dogs. Because malignancy was considered, laparoscopic partial nephrectomy 

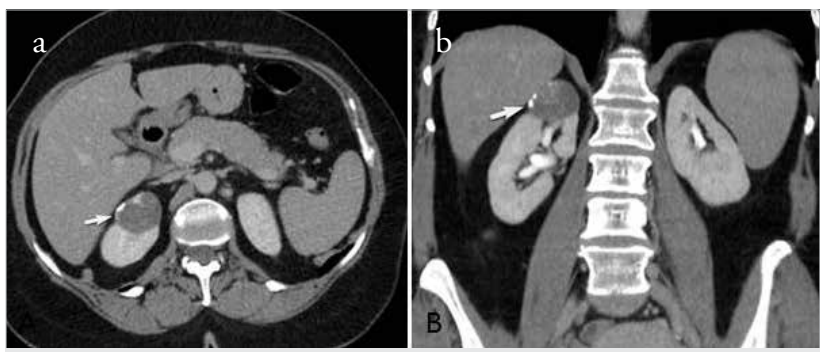

Figure 1. a, b. In axial (a) and coronal (b) computed tomography (CT) images, a smooth contoured lesion that is $37 \times 30 \mathrm{~mm}$ in size in the upper pole of the right kidney and a slight exophytic cortical lesion containing coarse calcifications in the lateral section and on the wall are observed (arrow)

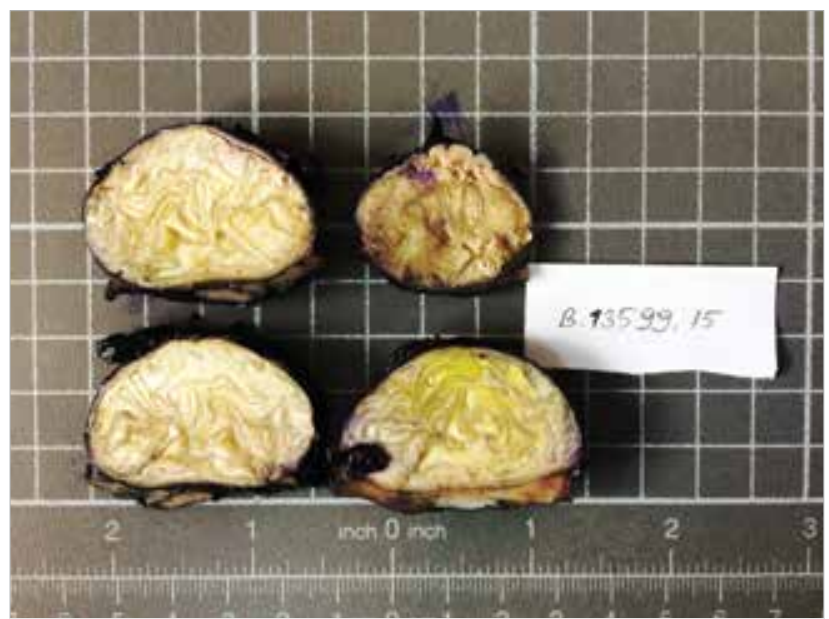

Figure 2. Macroscopic appearance of renal hydatid cyst

was performed without the need for serological tests, and the sample was sent to our department for pathological examination. A lesion containing yellow, occasionally off-white, soft consistency areas of lamellar structure sized $4.2 \times 3.6 \times 2.6$ $\mathrm{cm}$ was observed in the section of the partial nephrectomy sample that was macroscopically $6 \times 5 \times 3 \mathrm{~cm}$ in size. There were sporadic calcifications in the periphery of the lesion (Figure 2). Surgical margins were considered to be intact in the macroscopic examination. The lesion, which was separated from the surrounding renal tissue by a thick fibrous capsule, was observed in the microscopic examination (Figure 3). The lesion had a lamellar manner and contained an eosinophilic hyaline cuticular membrane, a giant cell reaction such as that around a foreign body, calcification areas, and mononuclear inflammatory cells (Figure 4). Rare glomerular global sclerosis was observed in the area of the kidney. In addition, there was hyalinization on the vessel wall, eosinophilic material in the tubule lumen, and mononuclear inflammatory cell infiltration in the interstitium. The lesion was consistent with renal hydatid cyst, according to the present findings. No findings were suggestive of malignancy. After the surgery, Echinococcus antibody was negative, at $1 / 80$ (normal $<1 / 160)$. Because the lesion was surgically removed without rupture, treatment was not needed after the surgery.

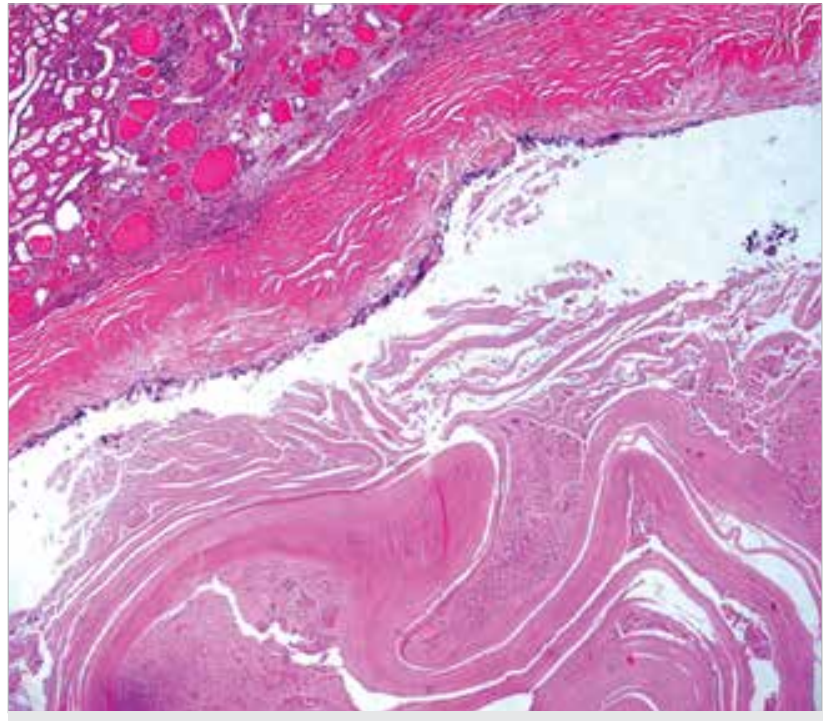

Figure 3 . The lesion separated from the surrounding kidney tissue by fibrous tissue $(H \& E \times 20)$

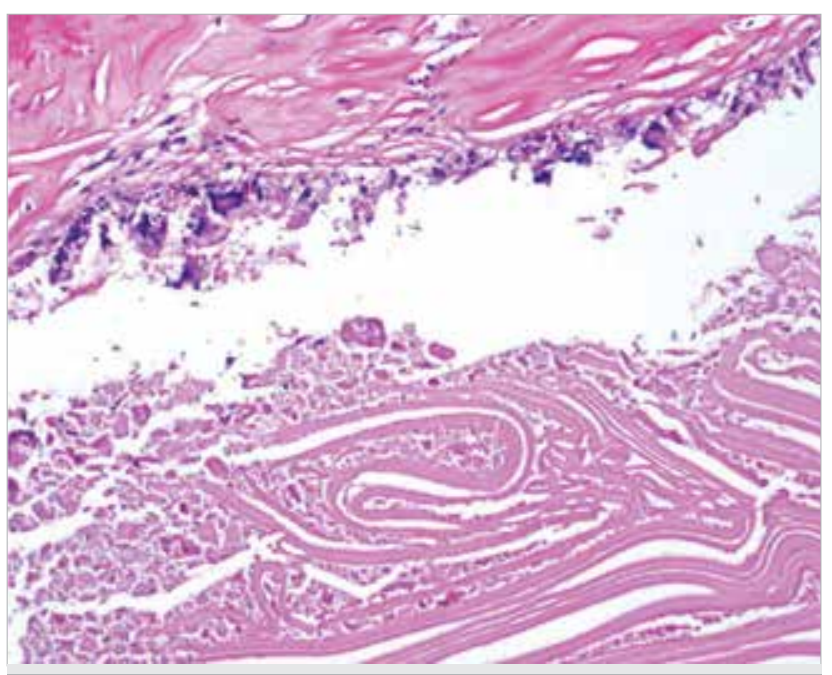

Figure 4. Lamellar cuticular membrane in eosinophilic view and giant cells around it (arrow) $(\mathrm{H} \& \mathrm{E} \times 100)$

\section{Discussion}

Hydatid cyst is an endemic parasitic disease that occurs by oral ingestion of E. granulosus larvae. The ingested larvae settle in the liver and other organs through the blood and lymph. Because the liver has the characteristic of being the first filter of organisms, it is the most commonly affected organ $(54 \%$ and $77 \%$ ). The larvae that are able to escape this filter cause lung involvement $(9 \%-30 \%)$. The spleen $(0.9 \%-8 \%)$, kidney $(2 \%-3 \%)$, and brain $(1 \%)$ are among the rarely affected organs $(1,2)$. It is quite slow for the larvae that settle in the organs to grow and cause symptoms, and the diagnosis can be made even 20-25 years after the infection (3). The kidney is the most common location in the urogenital system. Renal hydatid cyst causes symptoms with vague pain and/or a palpable mass in the lumbar region and is rarely associated with whitish genital discharge. In our case, the cyst was iden- 
tified incidentally. It has been reported that it settles in the left kidney more often than the right, and it is thought that this situation may be related to the fact that the left renal artery is shorter than the right renal artery $(4,5)$. In our case, the lesion was located in the right kidney. There is no specific laboratory test for detecting renal hydatid cyst. Although it is observed in $20 \%-50 \%$ of moderate eosinophilia cases, it is nonspecific (6). There was no eosinophilia in our case. Imaging methods are important for early diagnosis. Although ultrasonography is the most useful radiologic method, unenhanced CT and MRI have a high sensitivity for lesions. A hypointense and multicystic view is more apparent in MRI (7). According to the WHO/IWG-E classification based on the display and time of the cyst, echinococcosis was divided into three groups: active, transition, and inactive. The cyst can be unilocular or multilocular septal in case of active cysts. Although multicystic renal cell carcinoma and multicystic nephroma are included in differential diagnosis, a wheel-like and honeycomb appearance in the septa is valuable for the diagnosis of hydatid cysts. In inactive cysts, solid degeneration and calcification may be observed on the cyst wall. In our case, there was calcification in solid appearance and in the focal area of the cyst wall. In addition, although hydatid cyst is included in differential diagnosis, papillary renal cell carcinoma was mainly considered. Serological tests such as immunoelectrophoresis, immune hemagglutination, western blot, and complement fixation can help in diagnosis, though they are not very specific (8). In general, surgery is the best treatment option for hydatid cysts. Surgical procedures have puncture, aspiration, and injection stages. Before the surgery, the thorax and abdomen should be screened using imaging methods in a detailed manner. Partial nephrectomy is sufficient for renal hydatid cysts. Medical treatment with benzimidazole group drugs is recommended to sterilize the cyst preoperatively, to reduce the anaphylaxis risk and the tension of the cyst wall, and to reduce the risk of recurrence if the cyst is ruptured and spread inside the abdomen after the surgery (3).

\section{Conclusion}

Hydatid cyst is very rare in the kidney. Because it can radiologically be confused with malignancy before the surgery, it should be considered in terms of the differential diagnosis of the solid or cystic lesions that can create a mass effect in the kidney.

Informed Consent: Due to the retrospective natüre of this study, informed consent was waived.

Peer-review: Externally peer-reviewed.

Author Contributions: Concept - G.Ç.; Design - Z.O., G.Ç.; Supervision - G.Ç.; Resources - Z.O., G.Ç.; Data Collection and/or Processing - Z.O., N.Ü., S.K., Ü.T.; Analysis and/or Interpretation - G.Ç., Z.O., N.Ü.; Literature Search - Z.O., G.Ç.; Writing Manuscript - G.Ç., Z.O.; Critical Review - G.Ç., Z.O., S.K.; Other - Ü.T., S.K., N.Ü.

Conflict of Interest: No conflict of interest was declared by the authors.

Financial Disclosure: The authors declared that this study has received no financial support.

\section{References}

1. Kumar SA, Shetty A, Vijaya C, Geethamani V. Isolated primary renal echinococcosis: a rare entity. Int Urol Nephrol 2013; 45: 613-6. [CrossRef]

2. Horchani A, Nouira Y, Kbaier I, Attyaoui F, Zribi AS. Hydatid cyst of the kidney. A report of 147 controlled cases. Eur Urol 2000; 38: 461-7. [CrossRef]

3. Akkaya H, Akkaya B, Gönülcü S. Hydatid disease involving some rare sites in the body. Turkiye Parazitol Derg 2015; 39: 78-82. [CrossRef]

4. Rexiati M, Mutalifu A, Azhati B, Wang W, Yang H, Sheyhedin I, et al. Diagnosis and surgical treatment of renal hydatid disease: a retrospective analysis of 30 cases. PLoS One 2014; 9: e96602. [CrossRef]

5. Huang $\mathrm{M}$, Zheng $\mathrm{H}$. Clinical and demographic characteristics of patients with urinary tract hydatid disease. PLoS One 2012; 7: e47667. [CrossRef]

6. Göğüş C, Safak M, Baltaci S, Türkölmez K. Isolated renal hydatidosis: experience with 20 cases. J Urol 2003; 169: 186-9. [CrossRef]

7. Mongha R, Narayan S, Kundu AK. Primary hydatid cyst of kidney and ureter with gross hydatiduria: A case report and evaluation of radiological features. Indian J Urol 2008; 24: 116-7. [CrossRef]

8. Angulo JC, Sanchez-Chapado M, Diego A, Escribano J, Tamayo JC, Martin L. Renal echinococcosis: clinical study of 34 cases. J Urol 1997; 157: 787-94. [CrossRef] 